\title{
Brief Isoflurane Anesthesia Produces Prominent \\ Phosphoproteomic Changes in the Adult Mouse Hippocampus
}

\section{Kohtala, Samuel}

2016-06

Kohtala , S, Theilmann , W , Suomi , T, Wigren, H-K, Porkka-Heiskanen , T, Elo , L L , Rokka , A \& Rantamaki , T 2016 , ' Brief Isoflurane Anesthesia Produces Prominent Phosphoproteomic Changes in the Adult Mouse Hippocampus ' , ACS chemical neuroscience, vol. 7 , no. 6 , pp. 749-756 . https://doi.org/10.1021/acschemneuro.6b00002

http://hdl.handle.net/10138/224452

https://doi.org/10.1021/acschemneuro.6b00002

other

publishedVersion

Downloaded from Helda, University of Helsinki institutional repository.

This is an electronic reprint of the original article.

This reprint may differ from the original in pagination and typographic detail.

Please cite the original version. 


\title{
Brief Isoflurane Anesthesia Produces Prominent Phosphoproteomic Changes in the Adult Mouse Hippocampus
}

\author{
Samuel Kohtala, ${ }^{\dagger, \ddagger}$ Wiebke Theilmann, ${ }^{\dagger \neq, \perp}$ Tomi Suomi, ${ }^{\S, \perp}$ Henna-Kaisa Wigren,, \\ Tarja Porkka-Heiskanen, "Laura L. Elo, ${ }^{\S}$ Anne Rokka, ${ }^{\S}$ and Tomi Rantamäki ${ }^{*}, \dagger,+$ \\ ${ }^{\dagger}$ Faculty of Biological and Environmental Sciences, Department of Biosciences, Division of Physiology and Neuroscience, and \\ ${ }^{\ddagger}$ Neuroscience Center, University of Helsinki, FI-00014 Helsinki, Finland \\ ${ }^{\S}$ Turku Centre for Biotechnology, University of Turku, FI-20014 Turku, Finland \\ "Institute of Biomedicine, University of Helsinki, FI-00014 Helsinki, Finland
}

\section{Supporting Information}

\begin{abstract}
Anesthetics are widely used in medical practice and experimental research, yet the neurobiological basis governing their effects remains obscure. We have here used quantitative phosphoproteomics to investigate the protein phosphorylation changes produced by a $30 \mathrm{~min}$ isoflurane anesthesia in the adult mouse hippocampus. Altogether 318 phosphorylation alterations in total of 237 proteins between sham and isoflurane anesthesia were identified. Many of the hit proteins represent primary pharmacological targets of anes-

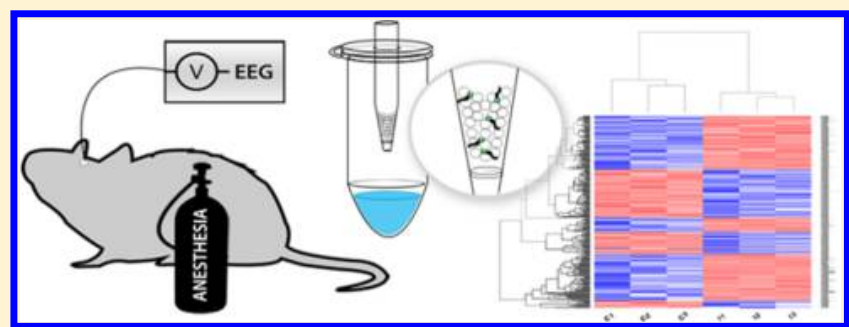
thetics. However, findings also enlighten the role of several other proteins-implicated in various biological processes including neuronal excitability, brain energy homeostasis, synaptic plasticity and transmission, and microtubule function-as putative (secondary) targets of anesthetics. In particular, isoflurane increases glycogen synthase kinase-3 $\beta$ (GSK $3 \beta$ ) phosphorylation at the inhibitory $\mathrm{Ser}^{9}$ residue and regulates the phosphorylation of multiple proteins downstream and upstream of this promiscuous kinase that regulate diverse biological functions. Along with confirmatory Western blot data for GSK3 $\beta$ and p44/42-MAPK (mitogen-activated protein kinase; reduced phosphorylation of the activation loop), we observed increased phosphorylation of microtubule-associated protein 2 (MAP2) on residues $\left(\mathrm{Thr}^{1620,1623}\right.$ ) that have been shown to render its dissociation from microtubules and alterations in microtubule stability. We further demonstrate that diverse anesthetics (sevoflurane, urethane, ketamine) produce essentially similar phosphorylation changes on GSK3 $\beta$, p44/p42-MAPK, and MAP2 as observed with isoflurane. Altogether our study demonstrates the potential of quantitative phosphoproteomics to study the mechanisms of anesthetics (and other drugs) in the mammalian brain and reveals how already a relatively brief anesthesia produces pronounced phosphorylation changes in multiple proteins in the central nervous system.
\end{abstract}

KEYWORDS: Anesthesia, protein phosphorylation, phosphopeptide enrichment, quantitative phosphoproteomics, glycogen synthase kinase- $3 \beta$

$\mathrm{T}_{\mathrm{i}}$ he discovery and development of anesthetics revolutionized and humanized surgical procedures. Each year millions of people undergo medical treatment requiring anesthesia(s). Anesthetics are also commonly used in veterinary medicine and in animal research. Volatile anesthetics, such as halogenated hydrocarbons isoflurane and sevoflurane, are among the most commonly used general anesthetics today. These drugs produce concentration-dependent rapid general anesthesia (unconsciousness, insensateness, analgesia, and amnesia) that is quickly recovered after the discontinuation of drug administration. The depth of anesthesia can be monitored using cortical electroencephalogram (EEG) whereby deep surgical anesthesia is characterized by intermittent shifts between almost flatline EEG and "packages" of spiking activity (i.e., EEG burst suppression). ${ }^{1}$

The mechanisms underlying the neurobiological actions and effects of anesthetics remain poorly understood. Early studies demonstrated that the anesthetic potency increases with mere lipid solubility and thus the effects of anesthetics were thought to rise through unspecific effects on cellular lipids. ${ }^{2}$ According to a more recent theory, anesthetics act predominantly by facilitating the opening of ligand-gated $\mathrm{GABA}_{\mathrm{A}}$ ( $\gamma$-aminobutyric acid) ion channel receptors and/or by dampening the opening of ligandgated NMDA ( $N$-methyl-D-aspartate) receptors. ${ }^{2,3} \mathrm{GABA}_{\mathrm{A}}$ receptors are responsible for the fast neuronal inhibition mediated by hyperpolarizing chloride $\left(\mathrm{Cl}^{-}\right)$currents in the adult mammalian CNS. ${ }^{4}$ NMDA receptors are activated by glutamate, the most abundant excitatory neurotransmitter in the nervous system. Although these pharmacological mechanisms are clearly demonstrated for anesthetic agents, anesthetics target, indirectly or directly, several other proteins as well. ${ }^{2}$ Surprisingly

Received: January 4, 2016

Accepted: April 13, 2016

Published: April 13, 2016 


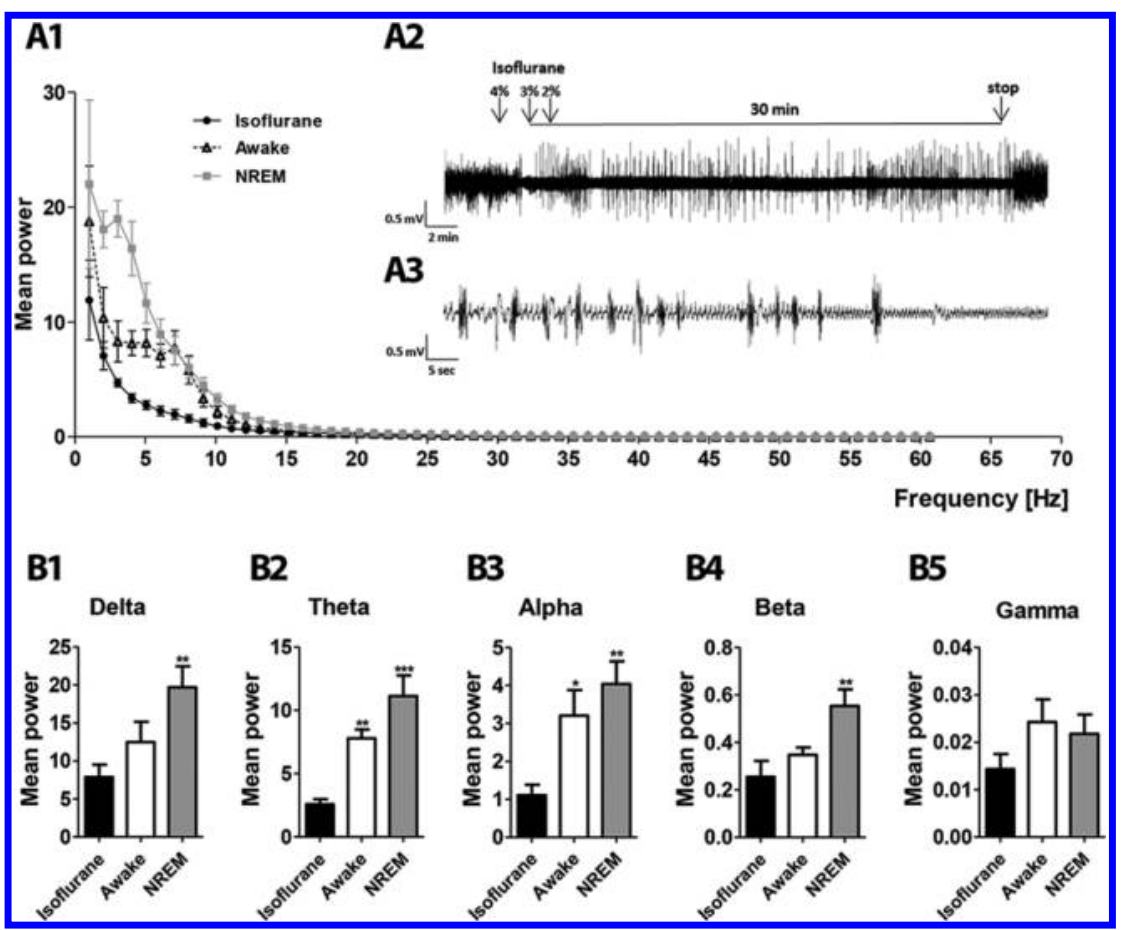

Figure 1. Effects of isoflurane anesthesia (4\% induction, $2 \%$ maintenance) on cortical EEG spectrogram and burst suppression. (A) EEG spectrogram during awake, non-REM (NREM) sleep, and under the influence of isoflurane (20-30 min recording). Representative traces of burst suppressing EEG shown in inset (A2) and (A3). (B) Quantitation of delta (1-4 Hz) (B1), theta (4-8 Hz) (B2), alpha (8-12 Hz) (B3), beta (12-30 Hz) (B4), and gamma $(30-60 \mathrm{~Hz})(\mathrm{B} 5)$ frequencies under the influence of isoflurane, during awake and NREM sleep. Deep burst-suppressing isoflurane anesthesia significantly reduces spectral power in frequency bands below $30 \mathrm{~Hz}$ when compared to baseline NREM sleep. EEG spectra were normalized to total EEG power for all frequencies within the baseline period recording. $N=5$; $p<0.05$, **p $<0.01$, ***p $p<0.001$; one-way ANOVA followed by Dunnett's multiple comparison test.

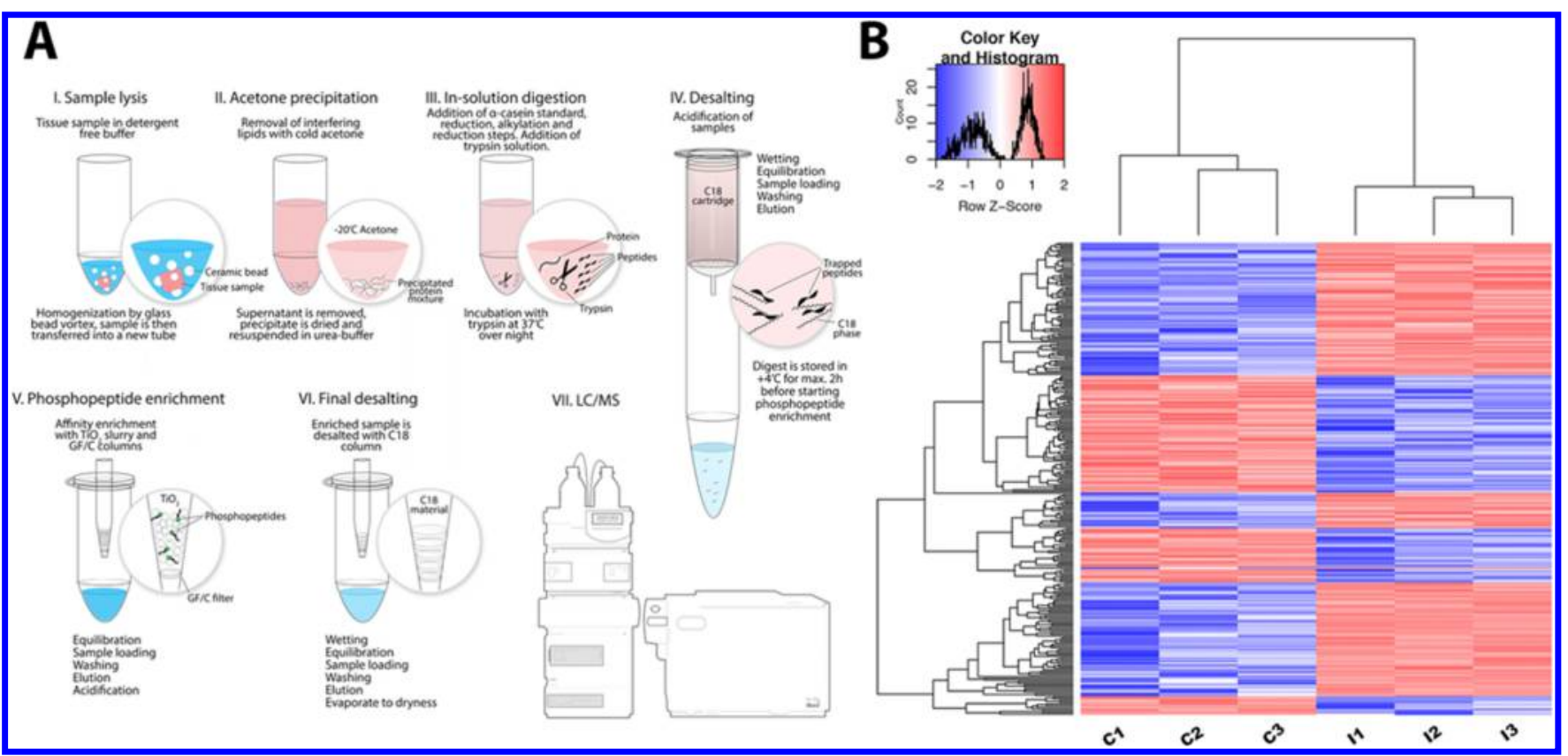

Figure 2. Phosphoproteomic workflow (A) and heat map (B) depicting differentially regulated phosphoproteins after sham (C1-C3) or 30 min isoflurane anesthesia (I1-I3) (4\% induction, $2 \%$ maintenance). $N=3$ /group.

little is known about the downstream intracellular changes and global intracellular signaling level alterations set fourth by the primary effects of anesthetics.

The functional consequences of short and long-term exposures to anesthesia have received considerable interest in recent decades. Anesthetics and sedatives have been shown to produce neuroapoptosis and atrophic neuronal changes, particularly during early development. ${ }^{5}$ However, the effects of anesthetics strongly depend on brain maturation stage, and the adult brain seems to be much less vulnerable for the deleterious effects of anesthetics. Yet, exposure to anesthetics in adult life may produce reversible amnesia and have been suggested to 
produce cognitive problems and even accelerate Alzheimer's disease pathology. ${ }^{6,7}$ On the other hand, brief deep anesthesia has also been shown to produce therapeutic effects against depression, stroke, and brain trauma. ${ }^{8-11}$ The neurobiological mechanisms and neurophysiological correlates underlying all of these effects of anesthetics remain poorly understood.

Protein phosphorylation is an important-transient-posttranslational modification that dynamically regulates the activity, folding, protein-protein interaction and cellular trafficking and targeting of many, if not most, proteins. ${ }^{12,13}$ Indeed, quantitative phosphoproteomics is becoming very efficient tool to investigate global signaling-level changes in biological systems. ${ }^{12}$ However, to our knowledge, no study has utilized this method to investigate phosphoproteomic alterations in samples obtained from the mammalian brain following anesthesia. We have here employed this method to study the effects of a single and brief isoflurane anesthesia on protein phosphorylation in the adult mouse hippocampus.

\section{RESULTS AND DISCUSSION}

Isoflurane anesthesia has been shown to produce a myriad of central effects, ranging from therapeutic to pathological alterations, yet the neurobiological correlates for these effects (as for those underlying anesthesia in general) are poorly understood. To elucidate this issue using quantitative phosphoproteomics, we first utilized pharmaco-EEG to validate an isoflurane treatment procedure that brings persistent and reproducible state of anesthesia in adult male mice. As shown in Figure 1, the treatment protocol consisting of $4 \%$ induction phase and maintenance at $2 \%$ of isoflurane strongly and reproducibly reduced cortical EEG power spectra during the $30 \mathrm{~min}$ treatment period and rapidly and sustainably led to burst suppression pattern characterized by intermittent periods of low and high (bursts) amplitude electrical activity. Induction and maintenance with $2 \%$ isoflurane produced similar, albeit less pronounced, EEG alterations in some but not all animals (data not shown). Notably, rapid anesthesia induction phase comprising initial high isoflurane concentration is commonly employed in animal experiments requiring surgical anesthesia (e.g., implantation of microdialysis probes or optogenetic wires).

Next the treatment protocol producing reproducible deep anesthesia was used for a new cohort of naive mice and their hippocampi were collected for the phosphoproteomic study (Figure 2). We focused our analysis to the hippocampus to ensure enough tissue for protein extraction and to ensure reproducible dissection. This is to our knowledge the first attempt to investigate the effects of anesthesia on global level protein phosphorylation in the adult mammalian brain using quantitative phosphoproteomics. The adult brain is rich in lipids, which need to be removed before analysis. Therefore, our protocol included lipid elimination followed by protein digestion and $\mathrm{TiO}_{2}$-based phosphopeptide enrichment (selectivity: phosphoserine/threonine $>$ phosphotyrosine). The heat map schematically depicting phosphopeptide alterations in individual animals subjected to either sham and isoflurane anesthesia demonstrates prominent differences between the treatment groups (Figure 2). Altogether 318 significant phosphoproteomic alterations in total of 237 different proteins between sham and anesthesia were identified (Supporting Information). These proteins are associated and functionally clustered into various biological processes, and the great majority of them are associated with protein phosphorylation, which also partially validates our analysis (Supporting Information).
According to prevailing theory, volatile anesthetics primary act by facilitating the inhibitory tone mediated by $\mathrm{GABA}_{\mathrm{A}}$ receptors and/or dampening excitatory neurotransmission. ${ }^{2}$ Although the exact binding site of isoflurane to $\mathrm{GABA}_{\mathrm{A}}$ receptors remains unknown, $\alpha$ and $\beta$ subunits are presumable targets. ${ }^{3}$ The phosphorylations of $\alpha_{1}$ (Gabral; $\left.\operatorname{Ser}^{373}, \mathrm{Thr}^{366}\right)$, which governs the sedative effects of benzodiazepines, ${ }^{14}$ and $\beta_{3}$ (Gabrb3; Ser ${ }^{394}$ ) subunits are regulated by isoflurane in our study (Table 1 ). The

Table 1. Isoflurane Anesthesia (4\% Induction, 2\% Maintenance; $30 \mathrm{~min}$ ) Induced Phosphorylation Changes on Selected Plasma Membrane Channels and Receptors ${ }^{a}$

\begin{tabular}{|c|c|c|c|c|}
\hline Accession & Symbol & Gene name & Phosphorylation & Regulation \\
\hline P62812 & Gabra1 & $\begin{array}{c}\text { gamma-aminobutyric acid (GABA) } \\
\text { A receptor, subunit alpha } 1\end{array}$ & Ser373, Thr366 & - \\
\hline P63080 & Gabrb3 & $\begin{array}{c}\text { gamma-aminobutyric acid (GABA) } \\
\text { A receptor, subunit beta } 3\end{array}$ & Ser394 & - \\
\hline Q01097 & Grin2b & $\begin{array}{l}\text { glutamate receptor, ionotropic, } \\
\text { NMDA2B (epsilon 2) }\end{array}$ & Ser1036,Tyr1039 & $\boldsymbol{r}$ \\
\hline P97772 & Grm1 & glutamate receptor, metabotropic 1 & Ser853 & 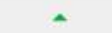 \\
\hline Q3UVX5 & Grm5 & glutamate receptor, metabotropic 5 & Ser860 & $\Delta$ \\
\hline Q68ED2 & Grm7 & glutamate receptor, metabotropic 7 & Ser873 & 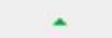 \\
\hline Q8R0S4 & Cacnb4 & $\begin{array}{l}\text { calcium channel, voltage- } \\
\text { dependent, beta } 4 \text { subunit }\end{array}$ & Ser434 & - \\
\hline P97445 & Cacna1a & $\begin{array}{l}\text { calcium channel, voltage- } \\
\text { dependent, } P / Q \text { type, alpha } 1 \mathrm{~A} \\
\text { subunit }\end{array}$ & Ser2030 & - \\
\hline 088703 & $\mathrm{Hcn} 2$ & $\begin{array}{l}\text { hyperpolarization-activated, cyclic } \\
\text { nucleotide-gated } \mathrm{K}+2\end{array}$ & Ser860 & - \\
\hline P48542 & Kcnj6 & $\begin{array}{l}\text { potassium inwardly-rectifying } \\
\text { channel, subfamily J, member } 6\end{array}$ & Ser25 & $\checkmark$ \\
\hline Q03717 & Kcnb1 & $\begin{array}{l}\text { potassium voltage gated channel, } \\
\text { Shab-related subfamily, member } 1\end{array}$ & Ser520 & $\boldsymbol{r}$ \\
\hline $\mathrm{A} 6 \mathrm{H} 8 \mathrm{H} 5$ & Kcnb2 & $\begin{array}{l}\text { potassium voltage gated channel, } \\
\text { Shab-related subfamily, member } 2\end{array}$ & Ser461 & - \\
\hline
\end{tabular}

${ }^{a}$ Green up triangle $=$ increased phosphorylation; red down triangle $=$ reduced phosphorylation.

phosphorylation of Grin $2 B$, the NMDA receptor subunit serving as the binding site for glutamate, is also regulated by isoflurane into two residues $\left(\mathrm{Ser}^{1036}, \mathrm{Tyr}^{1039}\right.$ ) (Table 1). In addition, three metabotropic glutamate receptors (Grm1, Grm5, Grm7) show phosphorylation changes in serine residues (Table 1). Several members of solute carriers, some of which regulate neurotransmitter reuptake (Slc1a2, Slc12a6, Slc4a8, Slc6a17, Slc9a1) are also differentially phosphorylated in response to isoflurane anesthesia (Supporting Information).

Several other ion channels have been also implicated as targets of anesthetics. These include glycine receptors, nicotinic acetylcholine receptors, $5-\mathrm{HT}_{3}$ receptors and several potassium $\left(\mathrm{K}^{+}\right)$, sodium $\left(\mathrm{Na}^{+}\right)$and calcium $\left(\mathrm{Ca}^{2+}\right)$ channels. Isoflurane anesthesia produced phosphorylation changes in four $\mathrm{K}^{+}$ channels (Hcn2, Kcnj6, Kcnb1-2) (Table 1). Of note, most anesthetics have been shown to block Hcn channel mediated $I_{h}$ currents $^{15-18}$ and Hcnl channels (although not found as a significant hit in the current study) have been shown to contribute to the hypnotic effects of anesthetics. ${ }^{15,19}$ Our data further suggests that anesthetics affect multiple mechanisms regulating $\left[\mathrm{Ca}^{2+}\right]_{\mathrm{i}}$ (Table 2$)$, including markedly altered phosphorylation of $\mathrm{Ca}^{2+}$-dependent secretion activator (Cadps), voltage dependent $\mathrm{Ca}^{2+}$ channels (Canb4, Cacnala), glutamate receptors, junctophilin $3(\mathrm{Jph} 3)$, ryanodine receptor 2, stromal interaction molecule 1 (Stim1), and a number of inositol trisphosphate $\left(\mathrm{IP}_{3}\right)$ related kinases and phosphatases. Phosphorylation-dependent alteration of the functionality of these regulators and effectors of $\mathrm{Ca}^{2+}$ signaling might result in the triggering of a variety of intracellular cascades leading into diverse outcomes, which is also supported by our data showing 
Table 2. Isoflurane Anesthesia (4\% Induction, 2\% Maintenance; 30 min) Induced Phosphoproteomic Changes on Selected Proteins Implicated in Intracellular Calcium Regulation and Homeostasis ${ }^{a}$

\begin{tabular}{|c|c|c|c|c|}
\hline Accession & Symbol & Gene name & Phosphorylation & Regulation \\
\hline Q9R0K7 & Atp $2 \mathrm{~b} 2$ & $\begin{array}{l}\text { ATPase, Ca++ transporting, } \\
\text { plasma membrane } 2\end{array}$ & Ser18 & - \\
\hline Q5HZ12 & $\mathrm{C} 2 \mathrm{~cd} 4 \mathrm{C}$ & $\begin{array}{l}\mathrm{C} 2 \text { calcium-dependent domain } \\
\text { containing } 4 \mathrm{C}\end{array}$ & Ser153 & - \\
\hline Q8R071 & Itpka & $\begin{array}{c}\text { inositol 1,4,5-trisphosphate 3- } \\
\text { kinase A }\end{array}$ & Ser20 & $\wedge$ \\
\hline P59644 & Inpp5j & $\begin{array}{c}\text { inositol polyphosphate 5- } \\
\text { phosphatase J }\end{array}$ & Ser987 & $\Delta$ \\
\hline Q8CDA1 & Inpp5f & $\begin{array}{l}\text { inositol polyphosphate-5- } \\
\text { phosphatase F }\end{array}$ & Ser915, Thr916 & 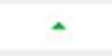 \\
\hline Q9ET77 & Jph3 & junctophilin 3 & Thr581 & $\checkmark$ \\
\hline Q3USB7 & Plcl1 & phospholipase C-like 1 & Thr94, Ser96 & $\sim$ \\
\hline \multirow[b]{2}{*}{ Q8K394 } & \multirow[b]{2}{*}{ PIcl2 } & \multirow{2}{*}{ phospholipase C-like 2} & Ser124 & $\sim$ \\
\hline & & & Thr585 & 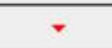 \\
\hline P63318 & Prkcg & protein kinase $\mathrm{C}$, gamma & Ser11 & 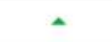 \\
\hline Q62074 & Prkci & protein kinase $\mathrm{C}$, iota & Thr563 & - \\
\hline E9Q401 & Ryr2 & ryanodine receptor 2 , cardiac & $\begin{array}{l}\text { Ser2807, } \\
\text { Ser2810, Ser2813 }\end{array}$ & - \\
\hline P70302 & Stim1 & stromal interaction molecule 1 & Ser567, Ser575 & $\sim$ \\
\hline Q80TJ1 & Cadps & $\begin{array}{c}\text { Ca2+-dependent secretion } \\
\text { activator }\end{array}$ & Ser91 & 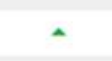 \\
\hline Q8КОTо & $R \operatorname{tn} 1$ & reticulon 1 & Ser487 & $v$ \\
\hline
\end{tabular}

${ }^{a}$ Green up triangle $=$ increased phosphorylation; red down triangle $=$ reduced phosphorylation.

numerous $\mathrm{Ca}^{2+}$ regulated targets with modified phosphorylation profiles. The intracellular release of $\mathrm{Ca}^{2+}$ is primarily dependent on two mechanisms, the inositol 1,4,5-trisphosphate receptors (InsP ${ }_{3} \mathrm{Rs}$ ) and the ryanodine receptors (RyRs), ${ }^{20}$ but other possible mediators are likely involved as well. ${ }^{21}$ The InsP $\mathrm{P}_{3} \mathrm{Rs}$ are regulated by the binding of $\mathrm{IP}_{3}$ that is generated by the exposure of cells to diverse stimuli, such as neurotrophic factors and neurotransmitters, which activate signaling through G-protein coupled receptors. ${ }^{22}$ The RyRs, however, are regulated directly by increases in $\left[\mathrm{Ca}^{2+}\right]_{\mathrm{i}}$. Aside from neuronal $\mathrm{Ca}^{2+}$ signaling, glial cells utilize $\mathrm{Ca}^{2+}$ in even more complex manner. ${ }^{23,24}$ Approximately half of the adult mammalian brain is comprised of astrocytes that participate in a wide array of functions, including synaptic transmission, neurotrophic signaling and structural support. $^{25}$

Some evidence indicate that PDZ (PSD-95/SAP90, Dlg, ZO1) domain mediated proteome disruption in the mechanisms of actions of anesthetics. ${ }^{26}$ Interestingly, isoflurane anesthesia produced differential phosphorylation in three PSD (postsynaptic density) protein family members (Dlgap 1-3) (Table 3 ), which act as scaffolding proteins in synaptic sites and orchestrate the functions and localization of proteins important for synaptic plasticity and neuronal transmission (e.g., NMDA receptors). According to our data search, several identified "hit" proteins are also associated with PDZ domain functionality (Shank2-3, Rims1, MIIt4, Arhgap21-23, Pclo, Lrrc7, Sipa1, Mast1) (Table 3, Supporting Information). Our data further shows that isoflurane anesthesia produces phosphorylation changes on several other proteins intimately implicated in synaptic plasticity, synapse formation, and function (Table 3).

Our study further strengthens previous studies pointing glycogen synthase $3 \beta(\mathrm{GSK} 3 \beta)$ as a target of anesthetics ${ }^{29}$ (Table 4 ). GSK3 $\beta$ is a promiscuous ${ }^{28}$ central serine-threonine kinase in several biological pathways critical for brain energy metabolism, microtubule stability, neuronal development,
Table 3. Isoflurane Anesthesia (4\% Induction, 2\% Maintenance; $30 \mathrm{~min}$ ) Induced Phosphoproteomic Changes on Selected Proteins Implicated in Synaptic Plasticity and Synapse Function ${ }^{a}$

\begin{tabular}{|c|c|c|c|c|}
\hline Accession & Symbol & Gene name & Phosphorylation & Regulation \\
\hline \multirow[t]{2}{*}{088737} & Bsn & bassoon & $\begin{array}{c}\text { Ser245, Ser249, } \\
\text { Ser789, Thr1404, } \\
\text { Ser1407, } \\
\text { Ser2805, } \\
\text { Ser2808, Ser2811, } \\
\text { Ser3231 }\end{array}$ & 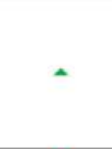 \\
\hline & & & Ser789 & 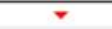 \\
\hline Q9D415 & Digap1 & $\begin{array}{l}\text { discs, large homolog-associated } \\
\text { protein } 1\end{array}$ & Ser421, Ser437 & 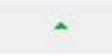 \\
\hline Q8BJ42 & Dlgap2 & $\begin{array}{l}\text { discs, large homolog-associated } \\
\text { protein } 2\end{array}$ & Ser670, Ser673 & $\boldsymbol{v}$ \\
\hline Q6PFD5 & Dlgap3 & $\begin{array}{c}\text { discs, large homolog-associated } \\
\text { protein } 3\end{array}$ & Ser779, Ser787 & $\sim$ \\
\hline Q9EPN1 & Nbea & neurobeachin & Thr1709 & $\boldsymbol{v}$ \\
\hline Q69ZK9 & Nlgn2 & neuroligin 2 & Ser714 & $\checkmark$ \\
\hline Q9QYX7 & Pclo & $\begin{array}{c}\text { piccolo (presynaptic cytomatrix } \\
\text { protein) }\end{array}$ & $\begin{array}{l}\text { Thr859, Thr860, } \\
\text { Ser2288 }\end{array}$ & $\wedge$ \\
\hline Q99NE5 & Rims1 & $\begin{array}{l}\text { regulating synaptic membrane } \\
\text { exocytosis } 1\end{array}$ & Thr1241 & 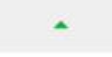 \\
\hline Q80U40 & Rimbp2 & RIMS binding protein 2 & $\begin{array}{c}\text { Tyr856, Ser859, } \\
\text { Thr861 }\end{array}$ & $r$ \\
\hline D3YZU1 & Shank1 & $\mathrm{SH}$ 3/ankyrin domain gene 1 & Ser977, Ser1907 & 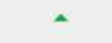 \\
\hline Q80Z38 & Shank2 & SH3/ankyrin domain gene 2 & Ser1334 & 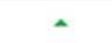 \\
\hline Q4ACU6 & Shank3 & $\mathrm{SH} 3$ /ankyrin domain gene 3 & $\begin{array}{l}\text { Ser1163, Ser1510, } \\
\text { Ser1638, Ser1640 }\end{array}$ & 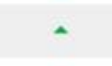 \\
\hline 008599 & Stxbp1 & syntaxin binding protein 1 & Ser506, Ser516 & - \\
\hline
\end{tabular}

${ }^{a}$ Green up triangle $=$ increased phosphorylation; red down triangle $=$ reduced phosphorylation.

synaptic plasticity, and inflammation. ${ }^{29,30}$ Specifically, GSK3 $\beta$ phosphorylation at the inhibitory residue $\operatorname{Ser}^{9}$ is significantly increased after isoflurane anesthesia. Alteration of GSK3 $\beta$ mediated signaling is further supported by phosphoproteomic data demonstrating differential phosphorylation of multiple proteins acting downstream or upstream of GSK $3 \beta$ including protein phosphatase 1 (PP1), ${ }^{29}$ microtubule-associated proteins 1-2 (MAP1-2), mitogen-activated protein kinase 3 (Mapk3, better known as p44-mitogen-activated protein kinase (p44MAPK)), phosphoinositide kinase, amyloid $\beta$ precursor protein, catenin $\Delta 1$, dynamin 1 , dystrophin, muscular dystrophy, phosphorylase kinase $\alpha_{2}$, and microtubule-associated protein tau (Table 4). ${ }^{30}$ Importantly, in addition to GSK3 $\beta$, we confirmed two of these isoflurane-induced phosphoprotein alterations, reduced phosphorylation of p44/42$\mathrm{MAPK}^{\mathrm{Thr} 202 / \mathrm{Tyr} 204}$ and increased phosphorylation of $\mathrm{p}$ -

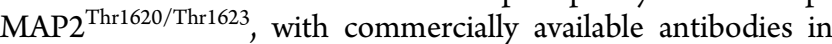
complementary animal experiments and Western blot analyses (Figure 3A).

Many of the hit proteins regulate actin cytoskeleton and microtubule dynamics (Table 4). Microtubules coordinate with other cytoskeletal components including microtubule associated proteins (MAPs) and actin filaments and play a critical role in neuronal cell morphology by establishing axons, dendrites and synapses, and maintaining them. ${ }^{32}$ This bundling activity of microtubules forms the basis for the scaffolding of the neuron and the synaptic architecture. MAPs, like MAP2 (Figure 3), are heavily regulated by phosphorylation, which affects their ability to bind and stabilize microtubules. ${ }^{31}$ Thus, the phosphorylation of MAPs can give rise to a variety of effects from the regulation of organelle transport to the anchorage of important signaling molecules, such as protein kinases and phosphatases. MAP2 has also been proposed to participate in the outgrowth of neuronal 
Table 4. Isoflurane Anesthesia (4\% Induction, 2\%

Maintenance; $30 \mathrm{~min}$ ) Induced Phosphoproteomic Changes on Selected Proteins Implicated in Glycogen Synthase Kinase $3 \boldsymbol{\beta}($ GSK $3 \boldsymbol{\beta})$ Signaling and Microtubule and Actin Dynamics ${ }^{a}$

\begin{tabular}{|c|c|c|c|c|}
\hline Accession & Symbol & Gene name & Phosphorylation & Regulation \\
\hline Q60598 & Cttn & cortactin & Ser47 & a \\
\hline Q62418 & Dbnl & drebrin-like & Ser277 & - \\
\hline P39053 & Dnm1 & dynamin 1 & Ser512 & * \\
\hline P11531 & Dmd & dystrophin, muscular dystrophy & Ser3616 & - \\
\hline Q9WV60 & Gsk3b & glycogen synthase kinase 3 beta & Ser9 & 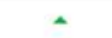 \\
\hline Q61792 & Lasp1 & LIM and SH3 protein 1 & Ser99 & 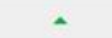 \\
\hline Q8VHJ5 & Mark1 & $\begin{array}{l}\text { MAP/microtubule affinity-regulating } \\
\text { kinase } 1\end{array}$ & Ser393 & $\boldsymbol{v}$ \\
\hline Q05512 & Mark2 & $\begin{array}{l}\text { MAP/microtubule affinity-regulating } \\
\text { kinase } 2\end{array}$ & Ser453 & - \\
\hline \multirow{2}{*}{ Q8CJ19 } & \multirow{2}{*}{ Mical3 } & \multirow{2}{*}{$\begin{array}{l}\text { microtubule associated } \\
\text { monooxygenase, calponin and LIM } \\
\text { domain containing } 3\end{array}$} & Ser1365 & 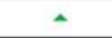 \\
\hline & & & Ser1404 & 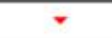 \\
\hline Q9R1L5 & Mast1 & $\begin{array}{l}\text { microtubule associated } \\
\text { serine/threonine kinase } 1\end{array}$ & Ser1112 & - \\
\hline Q3UHD3 & Mtus2 & $\begin{array}{l}\text { microtubule associated tumor } \\
\text { suppressor candidate } 2\end{array}$ & $\begin{array}{l}\text { Thr1319, } \\
\text { Ser1332 }\end{array}$ & 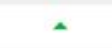 \\
\hline Q9QYR6 & Map1a & microtubule-associated protein $1 \mathrm{~A}$ & $\begin{array}{l}\text { Thr1575, } \\
\text { Ser1634 }\end{array}$ & 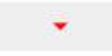 \\
\hline \multirow{2}{*}{ P14873 } & \multirow{2}{*}{ Map1b } & \multirow{2}{*}{ microtubule-associated protein $1 \mathrm{~B}$} & Ser1649 & 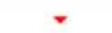 \\
\hline & & & Ser1793 & A \\
\hline P20357 & Map2 & microtubule-associated protein 2 & $\begin{array}{l}\text { Thr1623, } \\
\text { Thr1632, }\end{array}$ & - \\
\hline P27546 & Map4 & microtubule-associated protein 4 & Ser798 & 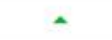 \\
\hline 088735 & Map7 & microtubule-associated protein 7 & Ser316 & - \\
\hline Q63844 & Mapk3 & mitogen-activated protein kinase 3 & Tyr205 & 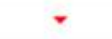 \\
\hline P10637 & Mapt & microtubule-associated protein tau & Ser688 & $\checkmark$ \\
\hline Q9QXS1 & Plec & plectin & $\begin{array}{l}\text { Ser4393, } \\
\text { Ser4396 }\end{array}$ & 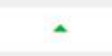 \\
\hline Q3UJU9 & Rmdn3 & regulator of microtubule dynamics 3 & Ser50 & $\checkmark$ \\
\hline Q5SW75 & Ssh2 & slingshot homolog 2 (Drosophila) & Ser487 & ^ \\
\hline P63042 & Stmn4 & stathmin-like 4 & Ser90 & 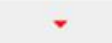 \\
\hline Q6PCN3 & Ttbk1 & tau tubulin kinase 1 & Ser484 & - \\
\hline Q8C5W3 & Tbcel & tubulin folding cofactor E-like & Ser18 & - \\
\hline P99024 & Tubb5 & tubulin, beta 5 class 1 & Ser275 & $\checkmark$ \\
\hline Q64727 & Vol & vinculin & Ser290 & - \\
\hline Q8R5H6 & Wasf1 & WAS protein family, member 1 & Ser339 & - \\
\hline
\end{tabular}

${ }^{a}$ Green up traingle $=$ increased phosphorylation; red down triangle $=$ reduced phosphorylation.

processes, synaptic plasticity and cellular death. ${ }^{31}$ Both GSK $3 \beta$ and MAPKs are known to phosphorylate MAP2 $2^{\text {Thr1620/1623 in }}$ vitro $^{33,34}$ and thereby cause MAP2 to lose its ability to effectively associate with the microtubules. ${ }^{35}$ However, our data, that shows significant phosphorylation at the inhibitory Ser9 residue of GSK $3 \beta$ and dephosphorylation of $\mathrm{p} 44 / 42-\mathrm{MAPK}$ at the activating loop residues Thr202/Tyr204, suggests alternative pathways for the phosphorylation of MAP2 following isoflurane anesthesia. For example $\mathrm{MAP} /$ microtubule affinity regulating kinases (MARKs), cyclin-dependent kinases (CDKs) and protein kinase $A$ and $C$ have been shown to regulate MAP2 phosphorylation. ${ }^{33,35,36}$ Regulation of the phosphorylation of MAP2 could also happen through the inhibition of specific phosphatases. Notably, our proteomic data shows phosphorylation changes in several members of MARKs and CDK family of kinases (Mark1, Mark2, Cdk11b, Cdk14 and Cdkl5) as well as proteins that regulate phosphatase (inhibitor) activity (e.g., Elfn2, Ppp1r1a and Ensa) (Table 4, Supporting Information).
In order to deepen the mechanistic insights of isofluraneinduced rapid phosphoproteomic alterations on GSK $3 \beta^{\mathrm{Ser} 9}, \mathrm{p} 44 /$ 42-MAPK ${ }^{\text {Thr202/Tyr204 }}$ and $\mathrm{MAP2}^{\text {Thr1620/Thr1623, we decided to }}$ study the effects of pharmacologically diverse anesthetics on these same residues. First, we investigated sevoflurane, a structurally and pharmacologically close relative of isoflurane, which produced similar phosphorylation changes on all three proteins (Figure 3B). Next, we assessed the effects of ethyl carbamate (better known as urethane). Urethane is commonly used in experimental animals because it produces strong analgesia and anesthesia but has minimal effects on cardiovascular/respiratory systems and baseline electrophysiological properties. However, also urethane anesthesia increased GSK3 $\beta$ and MAP2 phosphorylation and reduced p44/42MAPK phosphorylation (Figure 3C). The mechanism of action of urethane is poorly understood, but it has been shown to regulate several ion channels, including $\mathrm{GABA}_{\mathrm{A}}$ and NMDA receptors. ${ }^{37}$ Ketamine on the other hand specifically binds to and blocks NMDA receptors and thereby produces so-called dissociative anesthesia. Ketamine also produces very minor effects on cardiovascular/respiratory systems. However, it is more difficult to achieve deep anesthesia with ketamine monotherapy in experimental animals. Intriguingly, ketamine produced essentially similar changes on GSK $3 \beta$, p44/42-MAPK and MAP2 phosphorylation already at a sedative dose $(100 \mathrm{mg} /$ kg, i.p.) (Figure 3D).

Few proteomic studies have been performed to investigate the central effects of anesthetics but only a handful of proteins appear sustainably and reproducibly regulated by anesthetics. ${ }^{41,42}$ Protein phosphorylation is instead a very dynamic posttranslational modification that often critically alters the function of a given protein. To our knowledge this is the first study investigating phosphoproteomic changes induced by anesthesia in the adult mammalian brain. Although we took specific experimental focus (e.g., deep surgical anesthesia) and methodology (e.g., $\mathrm{TiO}_{2}$ more readily enriches phospho-serine/ threonine peptides compared to phospho-tyrosine), significant number of phosphorylation events appeared in known targets of anesthetics. However, the biological functions of many of the identified phosphorylation sites have not been described and further experiments and tools (e.g., antibodies) need to be performed and developed, respectively, to confirm and extend our observations.

Nevertheless, our study rationalizes the use of quantitative phosphoproteomics to investigate the neurobiological mechanisms and targets of anesthetics (and drugs in general) in the mammalian brain and demonstrates unexpectedly pronounced phosphorylation changes in multiple proteins in the central nervous system following already a brief anesthesia. Most interestingly, our pharmacological follow-up and confirmatory experiments clearly demonstrate that anesthesia (or sedation)irrespective of the pharmacological means inducing it-produce rapid (inhibitory) phosphorylation changes on GSK $3 \beta$ and $\mathrm{p} 44 /$ 42-MAPK, and phosphorylation alterations on MAP2 that render its dissociation from microtubules. Although the precise neurobiological basis and overall significance of these findings remain unclear it is important to note that regulation of GSK3 $\beta$ signaling and MAP2 has been implicated in the mechanisms of actions of neuroplastic treatments, antidepressants and mood stabilizers. $^{38-40}$ 


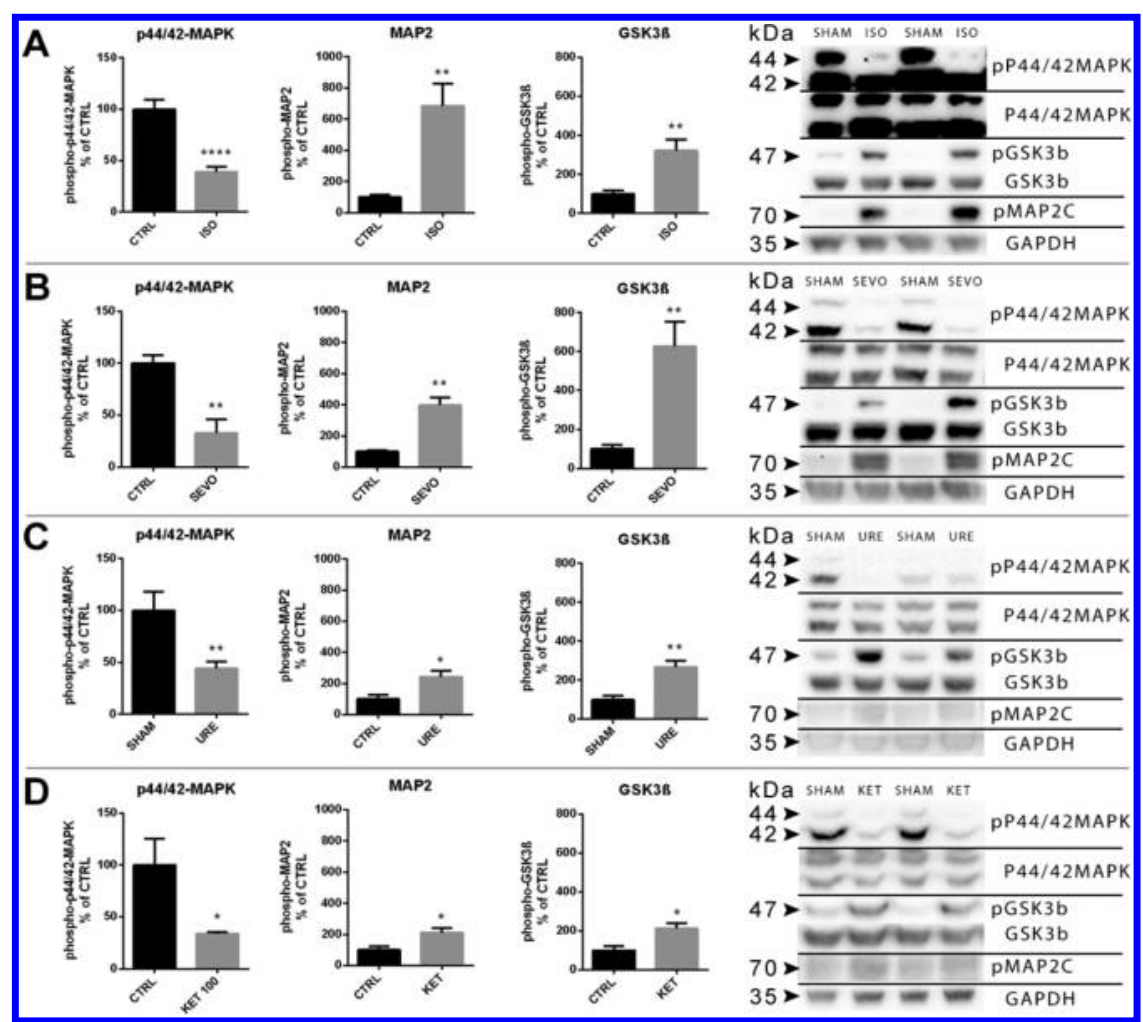

Figure 3. Diverse anesthetics produce similar acute phosphorylation changes on $\mathrm{p} 44 / 42-\mathrm{MAPK}^{\mathrm{Th} 202 / \mathrm{Ty} 204}, \mathrm{GSK} 3 \beta^{\mathrm{Ser} 9}$, and MAP2 $2^{\mathrm{Thr} 1620 / \mathrm{Thr} 1623}$ in the adult mouse hippocampus. (A) Effects of isoflurane anesthesia (4\% induction, $2 \%$ maintenance; $30 \mathrm{~min})(\mathrm{N}=10 /$ group). (B) Effects of sevoflurane anesthesia (6\% induction, $4.5 \%$ maintenance; $30 \mathrm{~min})(N=6 /$ group $)$. (C) Effects of urethane anesthesia $(2.0 \mathrm{~g} / \mathrm{kg}$, i.p.; $30 \mathrm{~min})(\mathrm{N}=4 / \mathrm{control}$ group, $N=6 /$ urethane group). (D) Effects of subanesthetic ketamine $(100 \mathrm{mg} / \mathrm{kg}$, i.p.; $30 \mathrm{~min})(N=6 /$ group $) . * p<0.05$, $* *<<0.01$, ****p< $*^{*} 0001$; twotailed unpaired $t$ test with Welch's correction. Abbreviations: MAPK, mitogen activated protein kinase; GSK3 $\beta$, glycogen synthase kinase 3 $\beta$; MAP2, microtubule-associated protein 2.

\section{METHODS}

Animals. The animal experiments were carried out according to the guidelines of the Society for Neuroscience and were approved by the County Administrative Board of Southern Finland (License: ESAVI/ 10527/04.10.07/2014). Adult male C57BL/6JRccHsd mice (Harlan Laboratories, Venray, Netherland) were used in the study. Animals were maintained in the animal facility of University of Helsinki, Finland, under standard laboratory conditions $\left(21^{\circ} \mathrm{C}, 12 \mathrm{~h}\right.$ light-dark cycle, lights on at 6 A.M.) with free access to food and water.

Drug Treatments. Unless otherwise stated the isoflurane (Vetflurane, Virbac) anesthesia was induced with 4\% isoflurane for 2 $\mathrm{min}$, after which the anesthetic concentration was gradually reduced to $2 \%$ for $30 \mathrm{~min}$ duration (oxygen flow: $0.3-0.51 / \mathrm{min}$ ). Sevoflurane (Sevorane, Baxter) anesthesia was induced with $6 \%$, after which the anesthetic concentration was gradually reduced to $4.5 \%$ for $30 \mathrm{~min}$ duration (oxygen flow: $0.3-0.5 \mathrm{l} / \mathrm{min}$ ). Sham mice were kept in the induction chamber without any oxygen or isoflurane/sevoflurane flow for $2 \mathrm{~min}$. Urethane ( $\mathrm{g} / \mathrm{kg}$; kindly provided by Dr. Kai Kaila, University of Helsinki) and ketamine (100 mg/kg; Ketaminol, Intervet) were injected intraperitoneally. Saline was injected in similar volume for the control group. Body temperature was maintained with a heat pad throughout the treatments.

EEG and EMG Recordings. For the implantation of electroencephalographic (EEG) and electromyographic (EMG) electrodes, mice were anesthetized with isoflurane anesthesia (4\% induction, 1.5$2 \%$ maintenance). Lidocaine $(10 \mathrm{mg} / \mathrm{mL})$ was used for local analgesia, and buprenorphine $(0.1 \mathrm{mg} / \mathrm{kg}$, s.c. $)$ for postoperative care. Two epidural screw EEG electrodes were placed above the fronto-parietal cortex. A further screw served as mounting support. Two silver wire electrodes were implanted in the nuchal muscles to monitor the EMG. After surgery, rats were single-housed in Plexiglas boxes. After a recovery period of 1 week, animals were connected to flexible counterbalanced cables for EEG/EMG recording and habituated to recording cables for 2 days. The EEG and EMG signals were amplified (EMG gain setting, $5 \mathrm{~K}$; EEG gain setting, $10 \mathrm{~K}$ ) and filtered (high pass, $1 \mathrm{~Hz}$; low pass, $100 \mathrm{~Hz}$ ) with a 16-channel AC amplifier (A-M System, model 3500), sampled at $254 \mathrm{~Hz}$ (EEG) or $70 \mathrm{~Hz}$ (EMG) with 1401 unit (CED), and recorded using Spike2 (version 6, Cambridge Electronic Devices). The processing of the EEG data was obtained using Spike2 (version 6, Cambridge Electronic Devices). EEG files were manually scored in $4 \mathrm{~s}$ epochs with Spike2 sleep scoring script Sleepscore 1.01 (CED) according to standard criteria: Non-REM sleep was recognized as high-amplitude EEG associated with low-voltage EMG and presence of slow delta $(1.0-4 \mathrm{~Hz})$ oscillations in the EEG, REM sleep as lowamplitude, high-frequency EEG with absence of EMG and presence of prominent EEG theta $(4-8 \mathrm{~Hz})$, and waking as low-amplitude, highfrequency EEG with high-voltage EMG. Artifacts or epochs with mixed states were marked and excluded from power spectral analysis. EEG power spectra were calculated within the $1-60 \mathrm{~Hz}$ frequency range by fast Fourier transform (FFT $=256$, Hanning window, $1.0 \mathrm{~Hz}$ resolution).

Phosphoprotein Enrichment and Quantitative Mass Spectrometry. Mice were killed by rapid cervical dislocation immediately after the treatment. Both hippocampi were dissected on a cooled dish as described and processed further for phosphoproteomic or confirmatory Western blot analyses. Phosphoproteomic analyses have been conducted essentially as described. ${ }^{43}$ Briefly, proteins were extracted from the brain samples by cutting the tissue with a razor blade and vortexing in the presence of glass beads $(0.5-5 \mathrm{~mm})$ in a detergent free lysis buffer containing broad-range protease and phosphatase inhibitors. After centrifugation protein concentrations were determined and sample tubes with equal amounts of total protein were prepared. Samples were then treated with ice-cold acetone to precipitate the proteins and to get rid of lipids that might hinder the subsequent analysis. The precipitates were dried, resuspended and prepared for 
digestion into peptides by trypsin. Phosphopeptides were enriched by titanium dioxide $\left(\mathrm{TiO}_{2}\right)$ using self-prepared microcolumns and analyzed subsequently by liquid chromatography tandem mass spectrometry (LC-MS/MS) method to define relative phosphoproteome changes. Notably, the phosphopeptide enrichment step multiplies the sensitivity to detect phosphoproteins, particularly serine and threonine residues.

Bioinformatics. Progenesis software (Nonlinear Dynamics, UK) was used for peptide quantification and the corresponding peptide identifications were performed using Mascot search through Proteome Discoverer (Thermo Fisher Scientific). The Progenesis-normalized peptide abundances of phosphorylated peptides were selected for differential expression analysis. The phosphosite locations in the peptide sequences were matched to locations in full protein sequence and peptides of the same protein having same phosphosites were summed. Abundances therefore represent phosphorylated proteins that have a specific combination of phosphosites. Significant differences in the abundances between the treatment groups were detected using reproducibility-optimized test statistic (ROTS), which selects a statistic from a family of $t$-type statistics based on the maximal overlap of topranked results in resamplings of the original data set. ${ }^{44}$ Phosphoproteomic alterations with false discovery rate (FDR) below 0.05 were considered as significant. Functional analyses were carried out using the DAVID tool, which is a biological knowledgebase integrated with different analytical tools. ${ }^{45}$ The functional annotation terms that were enriched in the list of differentially expressed phosphoproteins were determined using a modified Fisher's exact test (EASE score). Benjamini-Hochberg correction for multiple testing was used to control false discovery rate.

Western Blot. Western blotting was performed essentially as previously described. ${ }^{46,47}$ Briefly, the brain samples were homogenized in NP buffer (137 mM NaCl, $20 \mathrm{mM}$ Tris, $1 \% \mathrm{NP}-40,10 \%$ glycerol, 48 $\mathrm{mM} \mathrm{NaF}, \mathrm{H}_{2} \mathrm{O}$, Complete inhibitor mix (Roche), PhosphoStop (Roche)), incubated on ice, and centrifuged $(16000 \mathrm{~g}, 15 \mathrm{~min},+4$ ${ }^{\circ} \mathrm{C}$ ), and the resulting supernatant collected for further analysis. Sample protein concentrations were measured using Bio-Rad DC protein assay (Bio-Rad Laboratories, Hercules, CA). Samples ( $40 \mu \mathrm{g}$ protein) were separated with SDS-PAGE under reducing conditions and blotted to a PVDF (polyvinylidene difluoride) membrane. Membranes were incubated with the following primary antibodies: anti-p-GSK3 $3 \beta^{\text {Ser9 }}$ (\#9336, 1:1000, Cell Signaling Technology, (CST)), anti-p-p44/42MAPK $^{\text {Thr202/Y204 }}$ (\#9106, 1:1000, CST), anti-p-MAP2 ${ }^{\text {Thr1620/1623 }}$ (\#4544, 1:1000, CST), anti-GSK3 $\beta$ (\#9315, 1:1000, CST), anti-p44/ 42-MAPK (\#9102, 1:1000, CST), and anti-GAPDH (sc-25778, 1:10 000, Santa Cruz Biotechnology). Further, the membranes were washed with TBS/0.1\% Tween (TBST) and incubated with horseradish peroxidase conjugated secondary antibodies (1:10000 in nonfat dry milk, $1 \mathrm{~h}$ at room temperature; Bio-Rad). After subsequent washes, secondary antibodies were visualized using enhanced chemiluminescence (ECL Plus, ThermoScientific, Vantaa, Finland) for detection by Bio-Rad ChemiDoc MP camera (Bio-Rad Laboratories, Helsinki, Finland).

Statistics. The statistical analyses for the phosphoproteomic data were done using the $\mathrm{R}$ project (http://www.r-project.org) and Bioconductor (http://www.bioconductor.org). For the EEG data, one-way ANOVA followed by Dunnett's multiple comparison test was used. For the Western blot data, Student's $t$ test was used. Statistical significance was set to $<0.05$.

\section{ASSOCIATED CONTENT}

\section{S Supporting Information}

The Supporting Information is available free of charge on the ACS Publications website at DOI: 10.1021/acschemneur$0.6 \mathrm{~b} 00002$.

Table 1: Differentially regulated phosphoproteins after sham and isoflurane anesthesia (4\% induction, 2\% maintenance; $30 \mathrm{~min})(N=3 /$ group $)$. Phosphopeptide changes arranged based on statistical significance (FDR <
0.05). Table 2: Functional annotation clusters arranged based on the statistical significance $(F D R<0.05)$. (XLSX)

\section{AUTHOR INFORMATION}

\section{Corresponding Author}

* Mailing address: Faculty of Biological and Environmental Sciences, Department of Biosciences, Division of Physiology and Neuroscience, University of Helsinki, P.O. Box 65 (Viikinkaari 1), FI-00790 Helsinki, Finland. E-mail: tomi.rantamaki@ helsinki.fi. Phone: $+358-415020978$.

\section{Author Contributions}

${ }^{\perp}$ W.T. and T.S.: Equal contribution. S.K., W.T., T.S., H-K.W. performed the studies; S.K., W.T. and T.S., analyzed the data; S.K., W.T. and T.R. prepared the figures and tables. T.R. generated the original idea of the study. T.P-H., L.E., A.R. and T.R. planned and supervised the studies; S.K. and T.R. wrote the manuscript.

\section{Funding}

This study has been supported by the Academy of Finland (T.R.; grant no: 284569 and 276333) and Orion Research Foundation (S.K.)

Notes

The authors declare no competing financial interest.

\section{ACKNOWLEDGMENTS}

Mass spectrometry analysis was performed at the Turku Proteomics Facility, University of Turku and Åbo Akademi University. The facility is supported by Biocenter Finland. The authors would like to thank Maria Partanen for excellent technical assistance.

\section{REFERENCES}

(1) Amzica, F. (2009) Basic physiology of burst-suppression. Epilepsia 50, 38-39.

(2) Campagna, J. A., Miller, K. W., and Forman, S. A. (2003) Mechanisms of actions of inhaled anesthetics. N. Enol. I. Med. 348, $2110-2124$

(3) Garcia, P. S., Kolesky, S. E., and Jenkins, A. (2010) General Anesthetic Actions on GABAA Receptors. Curr. Neuropharmacol. 8, 29.

(4) Blaesse, P., Airaksinen, M. S., Rivera, C., and Kaila, K. (2009) Cation-chloride cotransporters and neuronal function. Neuron 61, 820838.

(5) Vutskits, L. (2012) General anesthesia: a gateway to modulate synapse formation and neural plasticity? Anesth. Analg. 115, 1174-1182.

(6) Kapila, A. K., Watts, H. R., Wang, T., and Ma, D. (2014) The impact of surgery and anesthesia on post-operative cognitive decline and Alzheimer's disease development: biomarkers and preventive strategies. I. Alzheimer's Dis. 41, 1-13.

(7) Whittington, R. A., Bretteville, A., Dickler, M. F., and Planel, E. (2013) Anesthesia and tau pathology. Prog. Neuro-Psychopharmacol. Biol. Psvchiatry 47, 147-155.

(8) Langer, G., Neumark, J., Koinig, G., Graf, M., and Schönbeck, G. (1985) Rapid psychotherapeutic effects of anesthesia with isoflurane (ES narcotherapy) in treatment-refractory depressed patients. $\underline{\text { Neuro- }}$ psvchobiology 14, 118-120.

(9) Engelhardt, W., Carl, G., and Hartung, E. (1993) Intra-individual open comparison of burst-suppression-isoflurane-anaesthesia versus electroconvulsive therapy in the treatment of severe depression. Eur. I. Anaesthesiol. 10, 113-118.

(10) Langer, G., Karazman, R., Neumark, J., Saletu, B., Schönbeck, G., Grünberger, J., Dittrich, R., Petricek, W., Hoffmann, P., and Linzmayer, L. (1995) Isoflurane narcotherapy in depressive patients refractory to conventional antidepressant drug treatment. A double-blind comparison with electroconvulsive treatment. Neuropsvchobiology 31, 182-194. 
(11) Doyle, P. W., and Matta, B. F. (1999) Burst suppression or isoelectric encephalogram for cerebral protection: evidence from metabolic suppression studies. Br. I. Anaesth. 83, 580-584.

(12) Liu, Y., and Chance, M. R. (2014) Integrating phosphoproteomics in systems biology. Comput. Struct. Biotechnol. I. 10, 90-97.

(13) Walaas, S. I., and Greengard, P. (1991) Protein phosphorylation and neuronal function. Pharmacol. Rev. 43, 299-349.

(14) McKernan, R. M., Rosahl, T. W., Reynolds, D. S., Sur, C., Wafford, K. A., Atack, J. R., Farrar, S., Myers, J., Cook, G., Ferris, P., Garrett, L., Bristow, L., Marshall, G., Macaulay, A., Brown, N., Howell, O., Moore, K. W., Carling, R. W., Street, L. J., Castro, J. L., Ragan, C. I., Dawson, G. R., and Whiting, P. J. (2000) Sedative but not anxiolytic properties of benzodiazepines are mediated by the $\mathrm{GABA}(\mathrm{A})$ receptor alpha1 subtype. Nat. Neurosci. 3, 587-592.

(15) Zhou, C., Liang, P., Liu, J., Ke, B., Wang, X., Li, F., Li, T., Bayliss, D. A., and Chen, X. (2015) HCN1 Channels Contribute to the Effects of Amnesia and Hypnosis but not Immobility of Volatile Anesthetics. Anesth. Analg. 121, 661-666.

(16) Bojak, I., Day, H. C., and Liley, D. T. J. (2013) Ketamine, propofol, and the EEG: a neural field analysis of HCN1-mediated interactions. Front. Comput. Neurosci. 7, 22.

(17) Carr, D. B., Andrews, G. D., Glen, W. B., and Lavin, A. (2007) alpha2-Noradrenergic receptors activation enhances excitability and synaptic integration in rat prefrontal cortex pyramidal neurons via inhibition of HCN currents. I. Phvsiol. 584, 437-450.

(18) Chen, X., Shu, S., Kennedy, D. P., Willcox, S. C., and Bayliss, D. A. (2009) Subunit-specific effects of isoflurane on neuronal Ih in HCN1 knockout mice. I. Neurophvsiol. 101, 129-140.

(19) Zhou, C., Douglas, J. E., Kumar, N. N., Shu, S., Bayliss, D. A., and Chen, X. (2013) Forebrain HCN1 channels contribute to hypnotic actions of ketamine. Anesthesiology 118, 785-795.

(20) Henzi, V., and MacDermott, A. B. (1992) Characteristics and function of $\mathrm{Ca}(2+)$ - and inositol 1,4,5-trisphosphate-releasable stores of $\mathrm{Ca} 2+$ in neurons. Neuroscience 46, 251-273.

(21) Takeshima, H., Venturi, E., and Sitsapesan, R. (2015) New and notable ion-channels in the sarcoplasmic/endoplasmic reticulum: do they support the process of intracellular $\mathrm{Ca}(2+)$ release? L. Physiol. 593, $3241-3251$.

(22) Ghosh, A., and Greenberg, M. E. (1995) Calcium signaling in neurons: molecular mechanisms and cellular consequences. Science 268, 239-247.

(23) Verkhratsky, A. J., and Petersen, O. H. (1998) Neuronal calcium stores. Cell Calcium 24, 333-343.

(24) Verkhratsky, A., Orkand, R. K., and Kettenmann, H. (1998) Glial calcium: homeostasis and signaling function. Phvsiol. Rev. 78, 99-141.

(25) Agulhon, C., Petravicz, J., McMullen, A. B., Sweger, E. J., Minton, S. K., Taves, S. R., Casper, K. B., Fiacco, T. A., and McCarthy, K. D. (2008) What is the role of astrocyte calcium in neurophysiology? Neuron 59, 932-946.

(26) Fang, M., Tao, Y.-X., He, F., Zhang, M., Levine, C. F., Mao, P., Tao, F., Chou, C.-L., Sadegh-Nasseri, S., and Johns, R. A. (2003) Synaptic PDZ Domain-mediated Protein Interactions Are Disrupted by Inhalational Anesthetics. I. Biol. Chem. 278, 36669-36675.

(27) Li, X., Friedman, A. B., Roh, M.-S., and Jope, R. S. (2005) Anesthesia and post-mortem interval profoundly influence the regulatory serine phosphorylation of glycogen synthase kinase- 3 in mouse brain. I. Neurochem. 92, 701-704.

(28) Linding, R., Jensen, L. J., Ostheimer, G. J., van Vugt, M. A. T. M., Jørgensen, C., Miron, I. M., Diella, F., Colwill, K., Taylor, L., Elder, K., Metalnikov, P., Nguyen, V., Pasculescu, A., Jin, J., Park, J. G., Samson, L. D., Woodgett, J. R., Russell, R. B., Bork, P., Yaffe, M. B., and Pawson, T. (2007) Systematic discovery of in vivo phosphorylation networks. Cell $129,1415-1426$.

(29) Peineau, S., Bradley, C., Taghibiglou, C., Doherty, A., Bortolotto, Z. A., Wang, Y. T., and Collingridge, G. L. (2008) The role of GSK-3 in synaptic plasticity. Br. I. Pharmacol. 153, S428-S437.

(30) Sutherland, C., and Sutherland, C. (2011) What Are the bona fide GSK3 Substrates? Int. I. Alzheimer's Dis. 2011, 505607.
(31) Sánchez, C., Díaz-Nido, J., and Avila, J. (2000) Phosphorylation of microtubule-associated protein 2 (MAP2) and its relevance for the regulation of the neuronal cytoskeleton function. Prog. Neurobiol. 61, $133-168$.

(32) Baas, P. W., Rao, A. N., Matamoros, A. J., and Leo, L. (2016) Stability properties of neuronal microtubules. Cytoskeleton, DOI: $10.1002 / \mathrm{cm} .21286$.

(33) Sánchez, C., Tompa, P., Szücs, K., Friedrich, P., and Avila, J. (1996) Phosphorylation and dephosphorylation in the proline-rich Cterminal domain of microtubule-associated protein 2. Eur. I. Biochem. $241,765-771$.

(34) Sánchez, C., Díaz-Nido, J., and Avila, J. (1998) Regulation of a site-specific phosphorylation of the microtubule-associated protein 2 during the development of cultured neurons. Neuroscience 87, 861-870.

(35) Sánchez, C., Pérez, M., and Avila, J. (2000) GSK3beta-mediated phosphorylation of the microtubule-associated protein 2C (MAP2C) prevents microtubule bundling. Eur. I. Cell Biol. 79, 252-260.

(36) Ebneth, A., Drewes, G., Mandelkow, E. M., and Mandelkow, E. (1999) Phosphorylation of MAP2c and MAP4 by MARK kinases leads to the destabilization of microtubules in cells. Cell Motil. Cutoskeleton 44, 209-224.

(37) Hara, K., and Harris, R. A. (2002) The anesthetic mechanism of urethane: the effects on neurotransmitter-gated ion channels. Anesth. Analg. 94, 313-318.

(38) Seira, O., and Del Río, J. A. (2014) Glycogen synthase kinase 3 beta $(\mathrm{GSK} 3 \beta)$ at the tip of neuronal development and regeneration. $\mathrm{Mol}$. Neurobiol. 49, 931-944.

(39) Li, X., and Jope, R. S. (2010) Is glycogen synthase kinase-3 a central modulator in mood regulation? Neuropsychopharmacology 35 , 2143-2154.

(40) Bianchi, M., and Baulieu, E.-E. (2012) 3 $\beta$-Methoxy-pregnenolone (MAP4343) as an innovative therapeutic approach for depressive disorders. Proc. Natl. Acad. Sci. U. S. A. 109, 1713-1718.

(41) Kalenka, A., Hinkelbein, J., Feldmann, R. E., Kuschinsky, W., Waschke, K. F., and Maurer, M. H. (2007) The Effects of Sevoflurane Anesthesia on Rat Brain Proteins: A Proteomic Time-Course Analysis. Anesth. Analg. 104, 1129-1135.

(42) Kalenka, A., Gross, B., Maurer, M. H., Thierse, H.-J., and Feldmann, R. E. (2010) Isoflurane Anesthesia Elicits Protein Pattern Changes in Rat Hippocampus. I. Neurosurg. Anesthesiol. 22, 144-154.

(43) Tan, H., Wu, Z., Wang, H., Bai, B., Li, Y., Wang, X., Zhai, B., Beach, T. G., and Peng, J. (2015) Refined phosphopeptide enrichment by phosphate additive and the analysis of human brain phosphoproteome. Proteomics 15, 500-507.

(44) Elo, L. L., Filén, S., Lahesmaa, R., and Aittokallio, T. (2008) Reproducibility-optimized test statistic for ranking genes in microarray studies. IEEE/ACM Trans. Comput. Biol. Bioinf. 5, 423-431.

(45) Huang, D. W., Sherman, B. T., and Lempicki, R. A. (2009) Bioinformatics enrichment tools: paths toward the comprehensive functional analysis of large gene lists. Nucleic Acids Res. 37, 1-13.

(46) Rantamäki, T., Hendolin, P., Kankaanpää, A., Mijatovic, J., Piepponen, P., Domenici, E., Chao, M. V., Männistö, P. T., and Castrén, E. (2007) Pharmacologically diverse antidepressants rapidly activate brain-derived neurotrophic factor receptor TrkB and induce phospholipase-Cgamma signaling pathways in mouse brain. Neuropsychopharmacology 32, 2152-2162.

(47) Rantamäki, T., Vesa, L., Antila, H., Di Lieto, A., Tammela, P., Schmitt, A., Lesch, K.-P., Rios, M., and Castrén, E. (2011) Antidepressant drugs transactivate $\operatorname{TrkB}$ neurotrophin receptors in the adult rodent brain independently of BDNF and monoamine transporter blockade. PLoS One 6, e20567. 